\title{
Two new Neotropical species of the genus Oxysarcodexia Townsend (Diptera, Sarcophagidae)
}

\author{
Wallace Faria Soares ${ }^{1} \&$ Cátia Antunes de Mello-Patiu ${ }^{1}$
} ${ }^{1}$ Departamento de Entomologia, Museu Nacional/UFRJ, Quinta da Boa Vista, s/nº, São Cristóvão, 20940-040 Rio de Janeiro-RJ, Brasil. wallace_soaress@
yahoo.com.br; catiapatiu@oi.com.br; camello@acd.ufrj.br

\begin{abstract}
Two new Neotropical species of the genus Oxysarcodexia Townsend (Diptera, Sarcophagidae). Oxysarcodexia nitida sp. nov. and $O$. notata sp. nov. from Peru are described and illustrated based on male specimens. These new taxa are morphologically more similar to $O$. vittata (Walker) and $O$. xon (Dodge) respectively.
\end{abstract}

KEY WORDS. Flesh flies; new species; Raviniini; Sarcophagidae; taxonomy.

RESUMO. Duas novas espécies neotropicais do gênero Oxysarcodexia Townsend (Diptera, Sarcophagidae). Oxysarcodexia nitida sp. nov. e $O$. notata sp. nov. do Peru são descritas e ilustradas com base em espécimes machos. Esses novos táxons são morfologicamente mais similares a $O$. vittata (Walker) e O. xon (Dodge), respectivamente.

PALAVRAS-CHAVE. Espécies novas; moscas-da-carne; Raviniini; Sarcophagidae; taxonomia.

Oxysarcodexia Townsend, 1917, included in the tribe Raviniini (Rohdendorf 1937; Lopes 1982), is one of the most species-rich genera of Sarcophagidae with 81 known species, most of them recorded from the Neotropical region, especially Brazil (Pape 1996). Their larvae are primarily coprophagous, but some of them can be predators (Tibana \& Mello 1985), and their adults are very abundant and often the most common flesh flies in field collections. Consequently, due to the high species diversity of this genus and the great similarity among the species, the specific segregation is a complex task.

Xarcophaga was proposed by Dodge (1968) as a monotypic genus, including only the nominal species $X$. xon, and it was distinguished from Oxysarcodexia by the elongated and slender phallus, with a characteristic apical enlargement. Lopes (1975) redescribed Oxysarcodexia pallisteri Dodge, 1966, transferred X. xon Dodge, 1968 to Oxysarcodexia, and considered both to be closely related to $O$. favorabilis (Lopes, 1935) and O. vittata (Walker, 1836). He did not corroborated Dodge's proposal and argued that it would be required an accurate study of females to assess the validity of the genus Xarcophaga. Later, Lopes (1982) included Oxysarcodexia, Xarcophaga, Apelophyla Hall and Hybopygia Enderlein into the subtribe Oxysarcodexiina (tribe Raviniini) as valid and distinct genera, and Pape (1996) synonymized all of them under Oxysarcodexia. Although the species of Oxysarcodexia (sensu lato) are well-documented in the literature, a major revision and a phylogenetic analysis are still required to provide explicit definitions and status to these taxa.

Oxysarcodexia species can be distinguished by the presence of a ctenidium of flattened spines in the male mid femur, postalar wall setose, tegula blackish and basicosta orange, male fifth sternite deeply cleft, a conspicuous vesica and three conducting styli in the phallus (Pape 1996; Silva \& Mello-Patiu 2008). The species segregation can be done based on examination of the phallus shape, the shape of the cercus apex, and especially of the vesica, which has projections and/ or lobes markedly distinct and ornamented.

In this paper, two new species of Oxysarcodexia from Peru are described and illustrated, both presenting the male terminalia very similar to those six species previously placed in Xarcophaga, i.e., with a characteristic enlarged apex of the phallus.

\section{MATERIAL AND METHODS}

Terminalia were dissected and cleared in boiling 10\% $\mathrm{KOH}$, and then washed in distillate water, and neutralized with acetic acid and 70\% ethanol (Silva \& Mello-Patiu 2008). They were studied in provisory microscope glass slides with glycerin and illustrations were prepared using a Motik 400 stereomicroscope and a Zeiss MC 80 microscope, both coupled with camera lucida. Terminology follows McAlpine (1981) for external morphology and Mello-Patiu \& Pape (2000) for genital structures. Type specimens were deposited in the collection of the Museu Nacional (MNRJ), Universidade Federal do Rio de Janeiro, Rio de Janeiro.

\section{RESULTS}

\section{Oxysarcodexia nitida sp. nov.}

(Figs. 1-4)

Type material. Holotype male, PERU: Avispas, Madre de Dios, 400m; 10-20. IX.1962, L. Peña col. (MNRJ)

Description. Male. Total length $=7 \mathrm{~mm}$.

Head: Fronto-orbital, parafacial, and post-ocular plates gray with light silvery microtomentum; frons about $0.2 \mathrm{X}$ head width at level of ocellar triangle; frontal vitta dark, with row of 8-9 frontal setae; inner vertical seta well-developed, 

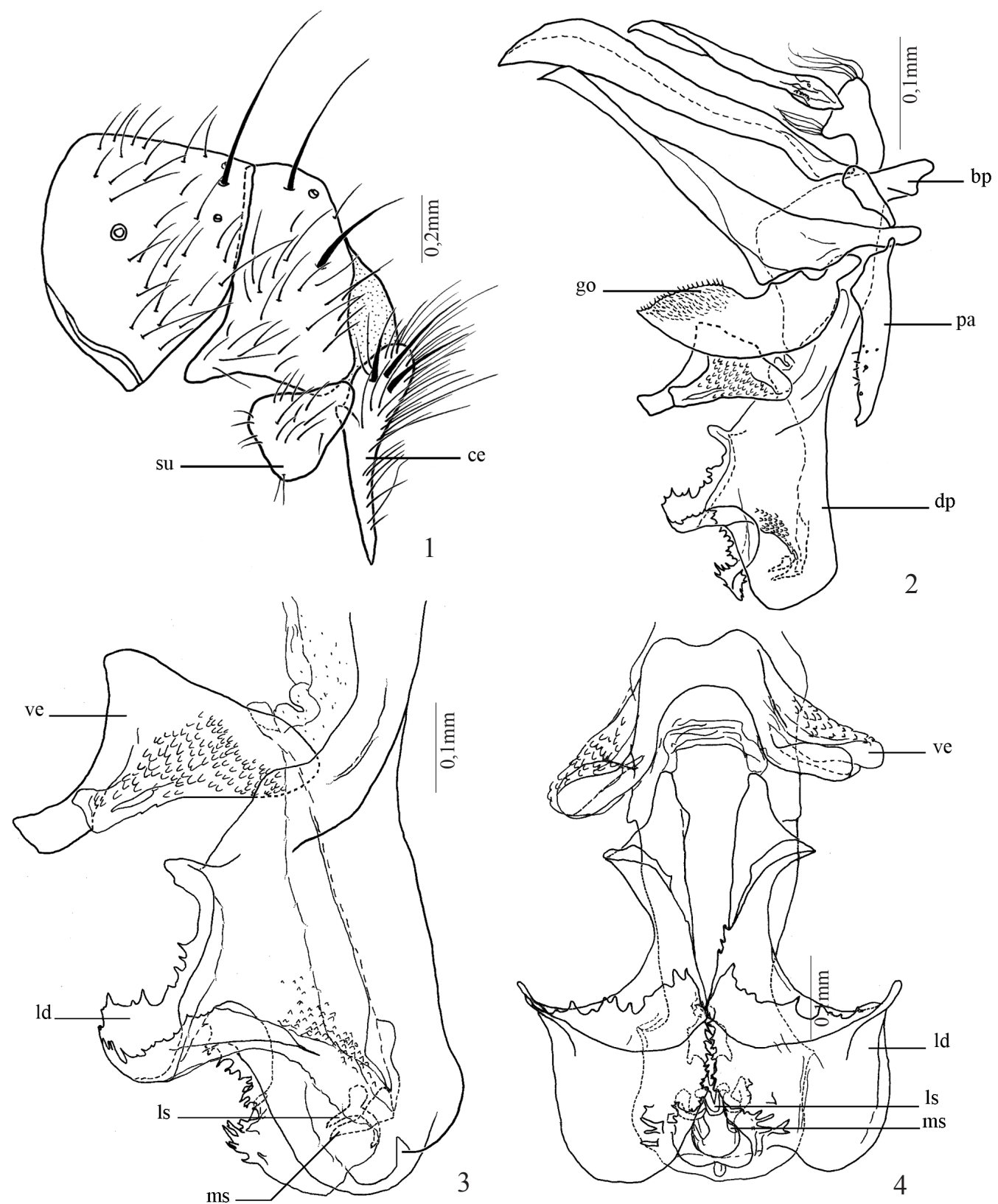

Figs. 1-4. Oxysarcodexia nitida sp. nov., male: 1, epandrium, cercus and surstylus, ateral view; 2 , phallus and associated structures, lateral view; 3 , distiphallus, lateral view; 4 , distiphallus, ventral view. Abbreviations: $\mathrm{bp}=$ basiphallus, ce= cercus, $\mathrm{dp}=$ distiphallus, go= gonopod, ld= lateral lobe of distiphallus, $1 \mathrm{~s}=1 \mathrm{ateral}$ stylus, $\mathrm{ms}=$ median stylus, $\mathrm{pa}=$ paramere, $\mathrm{su}=$ surstylus, $\mathrm{ve}=$ vesica.

outer vertical seta not differentiated; ocellar setae similar to uppermost frontals; reclinate fronto-orbital seta more developed than frontals and proclinate absent; gena and postgena with grayish microtomentum and black setae; antenna dark brown, first flagellomere grayish and $2 \mathrm{x}$ longer than pedicel; arista long plumose on basal 3/4; palpus dark brown.

Thorax: Gray with light golden microtomentum; chaetotaxy: acrosticals $0+1$, dorsocentrals $3+3$, intraalars $2+2$, supra-alars $2+3$, postalars 2 , postpronotals 2 , notopleurals 4 (2 large primaries and 2 smaller subprimaries), katepisternals 3 (middle one weaker, inserted slightly below others), meropleurals 8 , postalar wall setose, scutellum with one preapical, no apical, two strong and one weak laterals; prosternum setose in almost full extension. Wings: Hyaline, tegula small and black, $\mathrm{R}_{1}$ bare, $\mathrm{R}_{4+5}$ setulose in proximal 0.5 of distance to $\mathrm{r}-\mathrm{m}$, costal spine not differentiated, and third costal sector with ventral setulae. Legs: blackish brown, anterior femur with a row of setae on dorsal, posterodorsal, and posteroventral surfaces; mid femur with 3 median anterior and 2 pre-apical posterior setae, ctenidium apically on posteroventral surface, one posteroventral and one anteroventral row of long setae; mid tibia with one anterior and one posterodorsal seta; hind femur with a strong anteroventral and a pre-apical posterior seta, and one anterodorsal row of setae; hind tibia with one anterior, one median anteroventral, 2 median and 1 apical posterodorsal setae, one posterior and one posteroventral seta. 

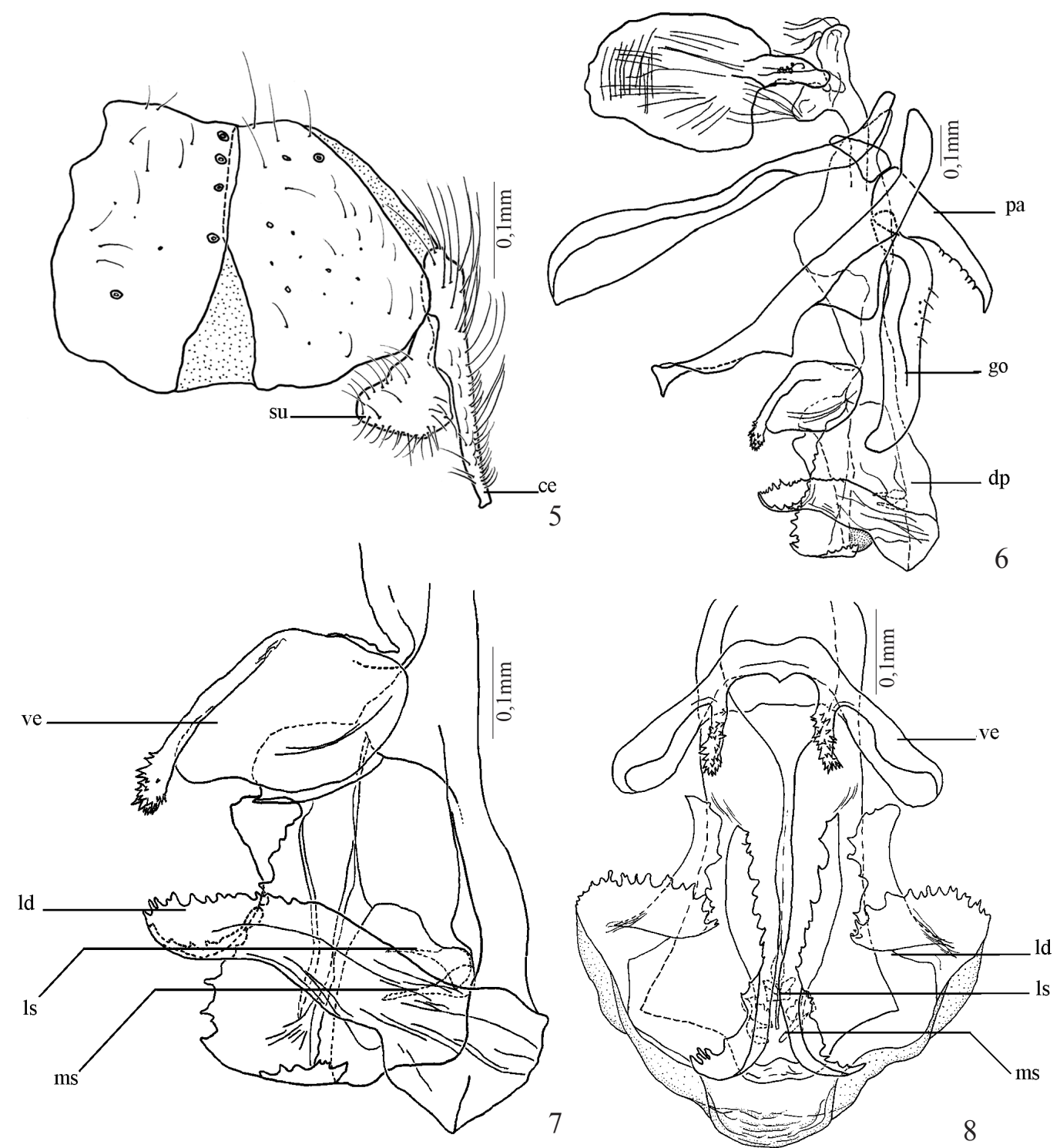

Figs. 5-8. Oxysarcodexia notata sp. nov., male: 5, epandrium, cercus and surstylus, lateral view; 6, phallus and associated structures, lateral view; 7, distiphallus, lateral view; 8, distiphallus, ventral view. Abbreviations: $\mathrm{bp}=$ basiphallus, ce $=$ cercus, $\mathrm{dp}=$ distiphallus, $\mathrm{go}=\mathrm{gonopod}$, $\mathrm{ld}=1$ lateral lobe of distiphallus, $1 \mathrm{~s}=1$ ateral stylus, $\mathrm{ms}=$ median stylus, $\mathrm{pa}=$ paramere, $\mathrm{su}=$ surstylus, $\mathrm{ve}=$ vesica.

Abdomen: Blackish brown with lightly golden microtomentum, laterally more intense; tergite 3 with one marginal lateral seta; tergite 4 with one pair of median marginals and 2 marginal lateral setae; tergite 5 with about 14 strong setae along the posterior margin; sternites $2-4$ subsquare-shaped; sternite 4 with stronger setae on posterior margin; sternite 5 with a median deep cleft. Terminalia. Cercus slightly curved forward, with a pointed apex; surstylus pear-shaped, with sparse marginal and discal setulae (Fig. 1); paramere elongated, slender, and slightly curved, with few setulae on anterior surface; gonopod broad with a set of many small setulae on the apical 1/3 of the anterior surface (Fig. 2). Phallus well sclerotized, no division between basi- and distiphallus, with an enlarged apex in ventral view (Fig. 4), a membranous and dentate edge along the ventral opening, and a lateral wavy lobe with dentate margin (Fig. 3); juxta absent; lateral and median styli small and apically positioned; median stylus short and broad (Fig. 4); vesica triangular with two lateral projections, the outer one less sclerotized and scales adorned (Figs. 3, 4).

Female. Unknown.

Etymology. From the Latin, nitidus = bright, shining, clear; the species epithet refers to the bright and shiny appearance of the male terminalia.

Comments. This species is morphologically very similar to O. vittata (Walker) and differs especially by the shape and adornment of vesica, the apex of the distiphallus and the characteristic gonopod.

\section{Oxysarcodexia notata sp. nov.}

(Figs. 5-8)

Type material. Holotype male, PERU: Avispas, Madre de Dios, 400m; 20-30. IX.1962, L. Peña col. (MNRJ) 
Description. Male. Differs from $O$. nitida sp. nov. by the following: Head. Frontal setae $=9-10$.

Thorax. Blackish, with silver microtomentum; scutellum with one pair of apical setae. Wings: $R_{4+5}$ setulose in almost full extension. Legs: Mid femur with 4 median setae on anterior surface. Abdomen. Tergite 5 with about 20 posterior marginal setae.

Terminalia. Cercus with slightly truncate apex; surstylus pear-shaped, with setulae along entire margin (Fig. 5); gonopod simple and narrow, with few setulae on posterior margin (Fig. 6); phallus with the characteristic dentate edge more ventrally expanded (Fig. 7) and lateral lobe more conspicuous (Figs. 7, 8); median stylus with apex more slender than the base (Fig. 8); vesica rounded, apex of the inner projections with strong spines (Figs. 7, 8).

Female. Unknown.

Etymology. From the Latin, notatus = noteworthy, marked, pronounced; the species epithet refers to the noticeable lateral lobe of the phallus.

Comments. The male terminalia are morphologically very similar to those of $O$. xon (Dodge), differing mainly by the characteristics of vesica and distiphallus.

Acknowledgements. We are grateful to the Conselho Nacional de Desenvolvimento Científico e Tecnológico - CNPQ for the scholarship to WFS (Proc. No 115553/2007-0), Fundação Carlos Chagas Filho de Amparo a Pesquisa do Estado do Rio de Janeiro - FAPERJ for the financial support to CAMP (Proc. N $\mathrm{N}^{\mathrm{O}} \mathrm{E}-26 / 110.239 / 2008$ ) and two anonymous referees for improving the paper with their suggestions.

\section{REFERENCES}

Dodge, H. R. 1968. The Sarcophagidae of Barro Colorado Island, Panama (Diptera). Annals of the Entomological Society of America 61: 421450.

Lopes, H. S. 1975. New or little known Oxysarcodexia (Diptera, Sarcophagidae). Revista Brasileira de Biologia 35: 461-483.

Lopes, H. S. 1982. The importance of the mandible and clypeal arch of the first instar larvae in the classification of the Sarcophagidae (Diptera). Revista Brasileira de Entomologia 26: 293-326.

McAlpine, J. F. 1981. Morphology and Terminology - Adults, p. 9-63. In: McAlpine, J. F. Peterson, B. V. Shewel, G. E. Teskey, H. J. Vockeroth, J. R. \& Wood, D. M. (coords.). Manual of Neartic Diptera. Vol. 2. Ottawa. Research Branch, Agriculture Canada, Monograph 28. vi+457 p.

Mello-Patiu, C. A. \& T. Pape. 2000. Definitions of Dexosarcophaga Townsend, 1917 and Sarcofartiopsis Hall, 1933, including two new species and redescriptions of Sarcofartiopsis cuneata (Townsend, 1935) (Diptera, Sarcophagidae). Boletin de Entomología Venezolana 15: 181-194.

Pape, T. 1996. Catalogue of the Sarcophagidae of the World (Insecta: Diptera), Memoirs on Entomology 8: 1-558.

Rohdendorf, B. B. 1937. Fam. Sarcophagidae, p. 1-501. In: Faune de I'URSS. Insectes Diptères 19(1). Moscow, Académie des Sciences de l' URSS.

Silva, K. P. \& C. A. Mello-Patiu. 2008. Morfologia comparada da terminália masculina de quatro espécies de Oxysarcodexia Townsend, 1917 (Diptera, Sarcophagidae). Arquivos do Museu Nacional 66: 363-372.

Tibana, R. \& C. A. Mello. 1985. O sintergito $6+7$ das fêmeas de Oxysarcodexia Townsend, 1917 (Dipt.Sarcop.). Revista Brasileira de Biologia 45: 439-445.

Received 07/04/2009; accepted 29/12/2009 